\title{
Driving cars to the clinic for solid tumors
}

\author{
Mauro Castellarin $^{1} \cdot$ Keisuke Watanabe ${ }^{1} \cdot$ Carl H. June $^{1}{ }^{1} \cdot$ Christopher C. Kloss $^{1} \cdot$ Avery D. Posey Jr. $^{1}$
}

Received: 26 October 2017 / Revised: 28 December 2017 / Accepted: 15 January 2018 / Published online: 7 June 2018

(c) The Author(s) 2018. This article is published with open access

\begin{abstract}
FDA approval of chimeric antigen receptor T cells (CART cells) is the culmination of several decades of technology development and interrogation of the properties of these gene therapies. CART cells exist as personalized "living drugs" and have demonstrated astounding anti-tumor efficacy in patients with leukemia and lymphoma. However, the future promise of CART efficacy for solid tumors, the greatest unmet burden, is met with a number of challenges that must be surmounted for effective immune responses. In this review, we discuss the next-generation developments of CARs to target solid tumors, including fine-tuned and combinational-targeting receptors. We consider the structural intricacies of the CAR molecules that influence optimal signaling and CART survival, and review pre-clinical cell-intrinsic and cell-extrinsic combinational therapy approaches.
\end{abstract}

\section{Introduction}

The recent FDA approval of tisagenlecleucel (Kymriah $^{\mathrm{TM}}$-Novartis) and axicabtagene ciloleucel (Yescarta $^{\mathrm{TM}}$-Kite) has ushered cancer medicine into the age of gene therapy. Both therapies use chimeric antigen receptors (CARs) genetically engineered into $\mathrm{T}$ cells (CART), empowering them to become precision tumor killers. First generated in the late 1980's, a CAR molecule contains an antigen-binding moiety (e.g., scFv) and a signaling motif (e.g., $\mathrm{CD} 3 \zeta$ ) necessary to generate an artificial $\mathrm{T}$ cell receptor (TCR). Subsequent CAR versions incorporated one or two costimulatory motifs and are commonly referred to as second or third-generation CARs, respectively. CARs allow for powerful harnessing of antigen-specific $\mathrm{T}$ cell responses by including potent stimulatory domains in virtually limitless numbers of $\mathrm{T}$ cells upon binding a desired antigen in an MHC-independent manner. CART cells have had tremendous success in leukemia and lymphoma (reviewed in Fesnak et al. [1]). Within this review, we will address four key parameters of engineering CART cells to eliminate solid tumors: targeting, optimal signaling,

Avery D. PoseyJr.

aposey@pennmedicine.upenn.edu

1 Center for Cellular Immunotherapies, Abramson Cancer Center and the Department of Pathology and Laboratory Medicine, Perelman School of Medicine, University of Pennsylvania, Philadelphia, PA, USA immunosuppression, and recruitment of innate immune cells.

\section{The next cart frontier: solid tumors}

The solid tumor microenvironment (TME) exerts three major barrier types to prevent effective anti-tumor immune responses [2] - environmental, inflammation, and immunosuppression (Fig. 1). The lack of CART efficacy in solid tumors can be due to the environmental barriers that exist (e.g., endothelial cell dysfunction [3], extracellular matrix barriers [4], hypoxia [5], lack of nutrients, or harsh conditions [6] preventing migration and infiltration to physically access the tumor. In addition, many tumors have chronic inflammation, which causes immunosuppressive molecules (e.g., TGF $\beta$, potassium, arginine, ferritin, prostaglandins, or leukotrienes) to be present in high concentrations within the tumor, which in turn induces recruitment of immunosuppressive immune cells (e.g., Tregs or myeloid-derived suppressor cells (MDSCs)). Furthermore, these immune cells and tumor cells highly express immune checkpoint inhibitor ligands (e.g., PD-L1, CD200, galectin-9, PVR, or B7-H4) to induce strong immunosuppression within the TME [7]. To improve CART function in solid tumors, it is important to address improvements in tumor targeting, defining optimal CAR structures and signaling domains, and synergizing CAR-T cells with the pro-immune and antitumor effects of oncolytic viruses, checkpoint inhibitors, and cytokine delivery. 


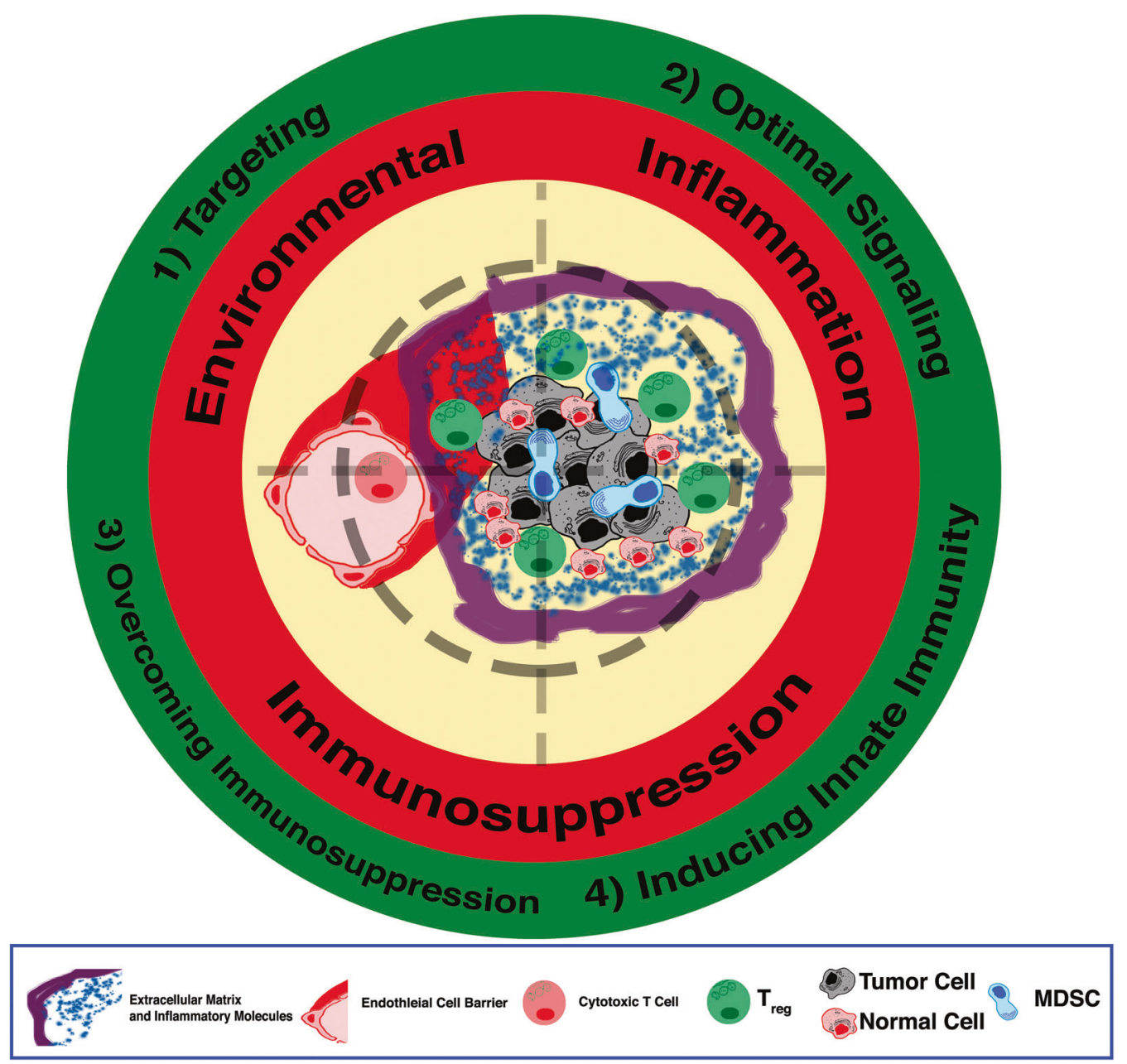

Fig. 1 Breaching the wall: targeting solid tumors for destruction. Solid tumors utilize multiple pathways to induce barriers, which include environmental factors that physically affect anti-tumor responses such as the extracellular matrix and inflammatory molecules as well as endothelial cell barriers. Inflammation barriers induce and recruit cells to create an immunosuppressive TME that inhibit immune responses from multiple angles, such as $\mathrm{T}$ regulatory (Treg) cells and myeloidderived suppressor cells (MDSCs). Cytotoxic CART cells should

\section{The antigen-binding domain: the navigation system}

The success of Kymriah and Yescarta for treating B cell malignancies is due, in large part, to the choice of the target antigen. Ideally, CAR targets are antigens on the cell surface, expressed on all tumor cells but not normal cells, are frequently shared between patients and contribute to the pathobiology of cancer, such that downregulation would hinder cancer growth. CD19 is a pan-B cell marker, highly abundant on the cell surface, present on most malignant B cells, and is required for signal transduction of the $\mathrm{B}$ cell receptor, which makes it critical for growth in many $\mathrm{B}$ cell cancers [8]. However, CART therapy induces B cell aplasia because CD19 is also found on healthy B cells. Fortunately, $B$ cell aplasia can be countered with intravenous utilize: (1) Targeting methods to combinatorial provide specificity to cancers cells, while sparing normal cells, (2) optimal signaling to induce potent and long-term immune responses to allow for long-term tumor eradication, (3) block suppressive signals to overcome immunosuppression, and (4) induce innate immunity by utilizing CART cells to deliver cytokines or in combination therapies with therapeutic antibodies and/or viruses

immunoglobulin replacement and methods are being developed to eliminate CARTs once the cancer is in remission $[9,10]$. Furthermore, the indiscriminate loss of $\mathrm{B}$ cells can be beneficial in removing both cancerous and precancerous $\mathrm{B}$ cells, thus reducing the chances of recurrence. Although B cell aplasia can be tolerated in patients with B cell malignancies, most solid tumors arise from organs or tissues that are indispensable, making the precise targeting of cancerous cells in solid tumors more critical.

Tumor antigens can be classified as either tumor-specific (found on tumor cells but with no or limited expression on normal cells) or tumor-associated (overexpressed on tumor cells but also found on normal cells at lower levels). Tumorspecific antigens (TSAs) include tumor mutations that result in aberrant protein sequences (e.g., EGFRvIII), oncofetal 
proteins that are transiently expressed during development but can be aberrantly in cancer cells (e.g., CEA), and testisassociated antigens, which are normally expressed in tissues that do not express MHC and therefore are not immunogenic (e.g., NY-ESO-1 in spermatozoa). Tumor-associated antigens (TAAs) include overexpressed proteins (e.g., HER2), post-translationally altered proteins (e.g., MUC1), or oncoviral proteins (e.g., HPV E7). A summary of tumor antigens that are currently being targeted in CART cell clinical trials is shown in Table 1 . Of note, significant solid tumor regression in the absence of severe toxicities has yet to be observed except in the case of one reported glioblastoma patient treated with intracranial infusions of a IL13R $\alpha 2$-targeting CAR [11].

\section{Affinity-tuned cars}

The use of TAAs to target solid tumors will remain limited unless CARTs can distinguish between tumor and normal cells beyond the presence or absence of a single antigen. More sophisticated tumor recognition can be achieved by programming $\mathrm{T}$ cells with CARs so that they work as comparative or Boolean operators (e.g., greater than, AND, OR, NOT) as shown in Fig. 2. Affinity-tuned CARs can discern between tumors that have a high density of antigens on their surface that is "greater than" the antigen density on normal cells. Tuning the affinity of a CAR can be done genetically by altering the $\mathrm{scFv}$ binding region via mutagenesis [12] or by recombining heavy and light chains [13]. Off-tumor toxicity from CART cells with high affinity for target antigen was observed in one patient that received trastuzumab-based HER2-CART cell therapy, which led to lethal cytokine release and cardiopulmonary toxicity [14]. Subsequently, animal models have demonstrated that affinity-tuning the CAR-T antigen-binding domain can improve safety by bypassing tissues with low antigen expression, while maintaining recognition and elimination of tumors with high antigen expression $[15,16]$.

Indeed, HER2-CARs can be used safely in the clinic, as shown in two clinical trials that administered FRP5-based HER2-CART cells to patients with either sarcoma [17] or glioblastoma [18]. The differences in safety between the trastuzumab (4D5) and FRP5-based therapies remain undetermined due to confounding clinical differences between trials. In contrast to the 4D5-based CART treatment, both of the FRP5-based clinical trials administered 2log lower maximum dose of cells, did not co-infuse lowdose IL-2, and did not employ a third-generation HER2CAR with a CD137 (4-1BB) signaling domain. Patients in the GBM trial received HER2-CAR-modified autologous virus-specific $\mathrm{T}$ cells (VSTs), which are postulated to increase $\mathrm{T}$ cell persistence. In addition, the patient treated with the trastuzumab CAR received cyclophosphamide and flurodarabine for lymphodepletion prior to therapy, while FRP5-CAR-treated patients received no lymphodepeletion. Lymphodepletion prior to CART treatment increases CART expansion by promoting expression of homeostatic cytokines and by removing inhibitory Tregs [19]. Overall, the FRP5-based HER2-CARs were well tolerated and some patients showed either a partial response or stable disease; however, there was no evidence of $\mathrm{T}$ cell expansion in either trial that is comparable to the CART expansion observed in patients with hematologic malignancies.

\section{Combinational-targeting CARs}

Another promising strategy for improving tumor recognition is simultaneous expression of different CARs according to "AND", "OR", "NOT" Boolean logic (Fig. 2). This strategy has been evaluated in pre-clinical studies, where dual CAR-T cells have targeted either CD19 “OR" CD123 antigens [20], MUC1 "OR" ErbB2 antigens [21], and even trivalent CART cells that can target HER2 "OR" IL13R $\alpha 2$ "OR" EphA2 [22]. In addition, $T$ cells can be engineered with a CAR and a transgenic TCR for recognition of an external CAR target "OR" an internal antigen presented by MHC [23]. As alternatives to expressing two separate antigen receptors, tandem CARs contain multiple contiguous antigen-binding domains so CAR-T cells can bind multiple antigens through a single receptor [24]. T cells can be programmed with the Boolean "NOT" logic by the co-expression of an activating CAR and an inhibitory CAR (iCAR), which delivers a PD-1 or CTLA-4 endodomain when its antigen is engaged [25]. This first description of iCARs was shown by Fedorov and colleagues, who expressed a CD19 CAR with a PSMA iCAR that killed $\mathrm{CD} 19^{+}$cells but "NOT" $\mathrm{CD} 19^{+} \mathrm{PSMA}^{+}$cells. Finally, the Boolean "AND" logic can be programmed into $\mathrm{T}$ cells by using either the split signal $[26,27]$ or SynNotch system [28]. The split signal approach uses dual CARs, each with different antigen-binding domains and either an activation or costimulation endodomain. Kloss and colleagues demonstrated that tumors expressing PSMA " $\mathrm{AND}^{+} \mathrm{PSCA}^{+}$ antigens were eliminated but not tumors expressing either antigen alone. Similarly, Lanitis et al. [27] developed a split signal CAR-T system that had potent lytic activity when the antigens, mesothelin and $\alpha$-folate receptor, were both expressed on the target cells but not when only one antigen was present. With the SynNotch system, T cells can be engineered with an antigen receptor that is tethered to an intracellular transcription factor. Once the receptor binds to its cognate antigen, the transcription factor is released and triggers the expression of a CAR that can now recognize a second antigen. Roybal and colleagues demonstrated that SynNotch T cells only killed tumor cells with dual expression of CD19 "AND" a surface GFP antigen. As promising as these new technologies are, they each have their own limitations that will 
Table 1 Antigens and indications targeted in CAR clinical trials for solid tumors

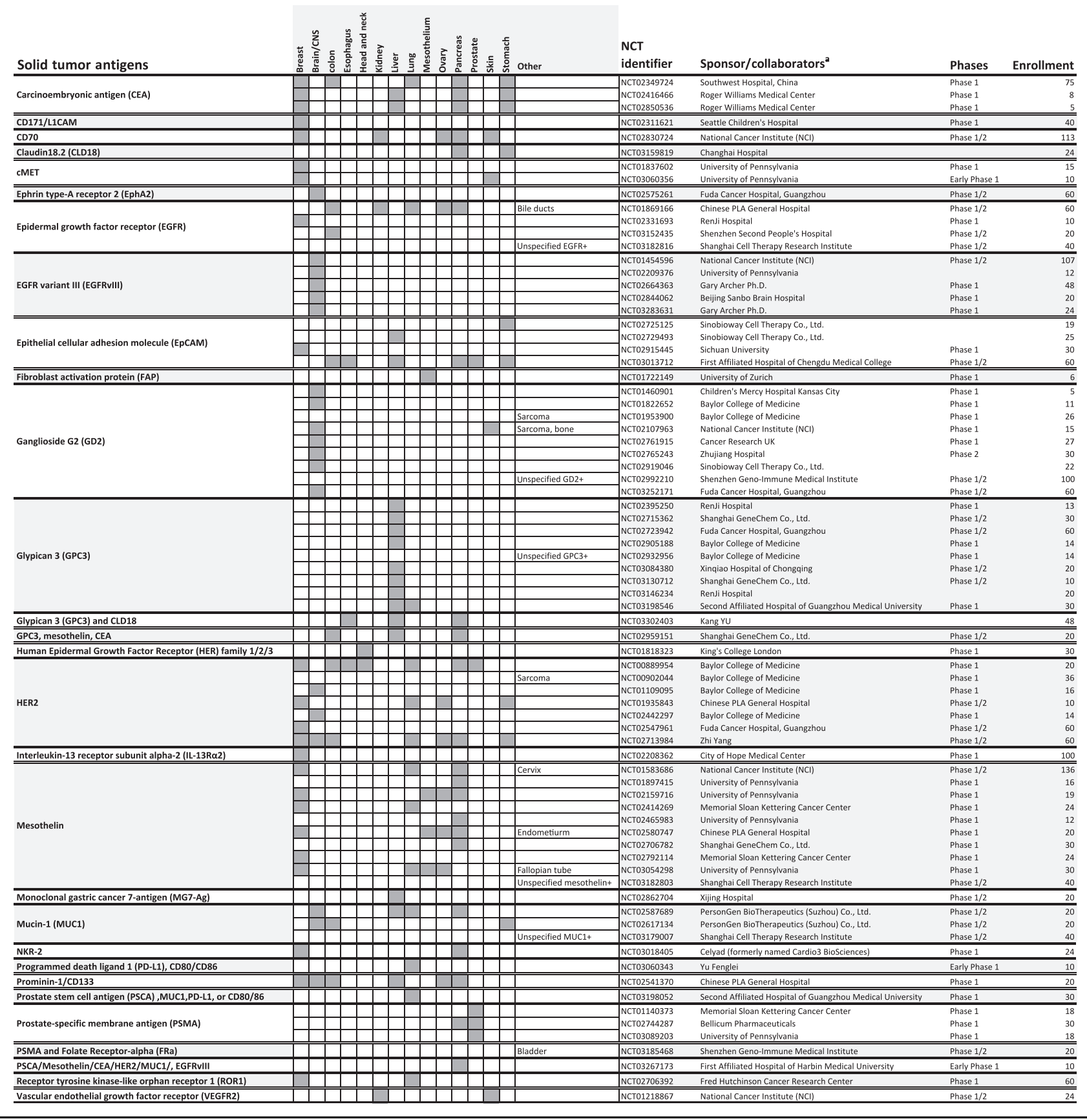

Source: ClinicalTrials.org

${ }^{\mathrm{a}}$ First listed

need to be overcome before they can be used in the clinic to treat solid tumor. CART cells programmed in the "OR" configuration are more likely to cause off-tumor toxicity, while CART cells in the "greater than", "NOT", "AND" configurations may be more permissive to cancer relapse due to tumor cell target loss and immune escape.

\section{Revving the engine}

Beyond the tumor-targeting domain of the CAR, there are several other domains that influence the cell-intrinsic functions of CART cells. Among these are the flexible extracellular spacer or hinge domain, the transmembrane, 


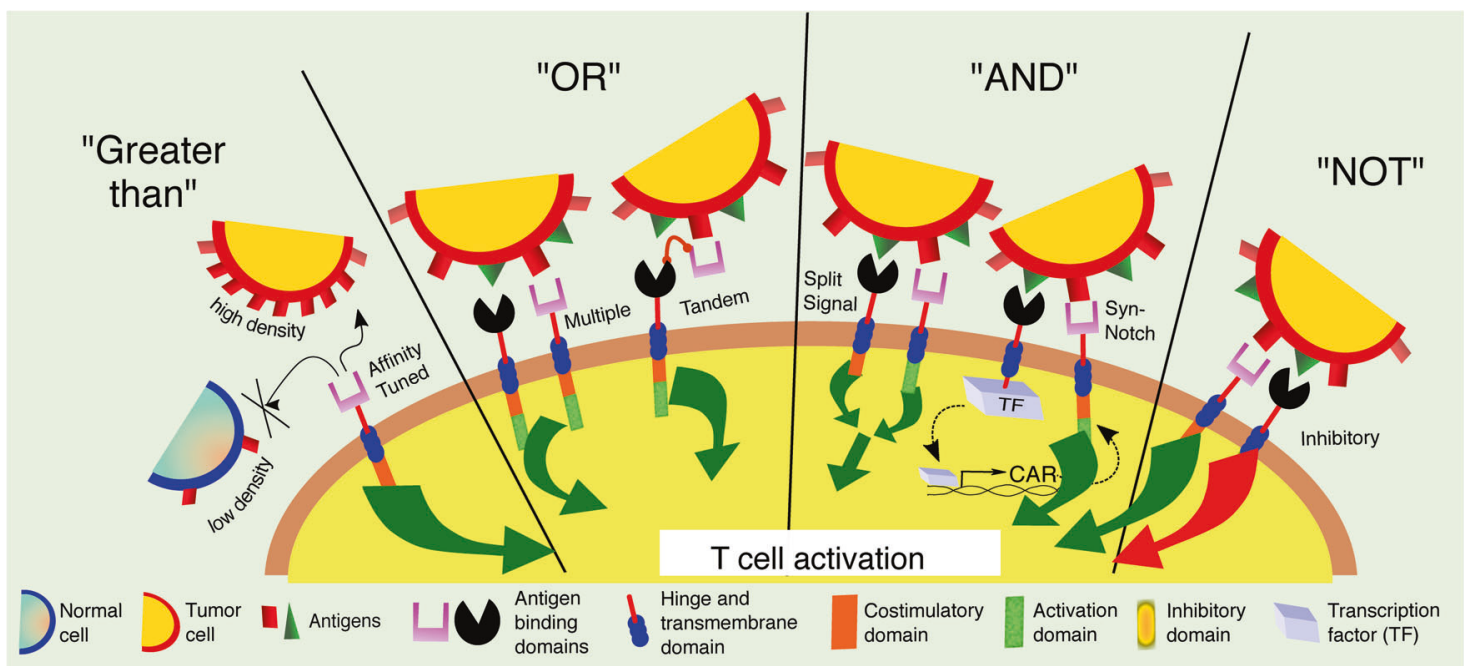

Fig. 2 Logical targeting: T cells can be programmed with CARs as comparative or Boolean operators to improve tumor targeting. Affinity-tuned CARs can recognize tumors with antigen densities that are "greater than" those found on normal cells. A single T cell can recognize one "OR" two different antigens when it expresses multiple CARs or expresses one CAR that is bound by tandem antigen-binding

and the costimulatory domain, which may yield the greatest control over anti-tumor efficacy. Although the structures of the clinically validated CARs have not differed greatly, significant pre-clinical modeling has demonstrated the necessity for CAR structural optimization and component interrogation. These activities will undoubtedly be critical for advancing CART cells in the treatment of solid tumors.

\section{The hinge: power steering}

The composition and length of the non-signaling, nontargeting flexible hinge influences the strength of the CAR response. For instance, the inclusion of an $\operatorname{IgD}$ spacer domain, and not the shorter CD28 hinge, as the hinge of an SM3-based CAR, which targets an unglycosylated peptide on MUC1, was necessary for CART cells to demonstrate cytotoxicity against $\mathrm{MUC1}^{+}$breast cancer cell lines [29]. Although hinge length influences CAR functionality in the context of some scFvs, these effects cannot completely be attributed to length, but also to composition. Mutation of the $\mathrm{N}$-linked glycosylation site in the IgG1 [30] or IgG4 [31] $\mathrm{CH} 2-\mathrm{CH} 3$ hinge improved CART persistence in vivo by ablating activation of the CAR through interaction of the CAR hinge with the FcyR1 on Ly6C ${ }^{+}$cells. As an example of the context-dependence of each CAR structure, CAR cells targeting ROR1 required the long IgG4-CH2-CH3 hinge for function and demonstrated no activity with short or intermediate hinge lengths, while CD19-CART cells with either a short 12 amino acid hinge or a long but mutated $\mathrm{IgG} 4-\mathrm{CH} 2-\mathrm{CH} 3$ hinge demonstrated superior tumor control in a leukemia xenograft model [31]. sites. T cells can be programmed to only kill targets that contain one antigen "AND" a second antigen. Targeting can be confined to cells that are engineered with one antigen but "NOT" a second antigen. Green and red arrows represent activating and inhibitory $\mathrm{T}$ cell signaling, respectively

The length of the CAR flexible hinge likely influences the strength of the CAR-to-antigen interaction and ultimately the immunological synapse formation in CART cells. CART cells demonstrate features that are characteristic of natural immune synapse formation, including the ability to exclude the CD45 phosphatase [32] as well as F-actin polymerization and lytic granule convergence around the microtubule organizing center [22]. It remains unclear how similar CART cell immune synapses are to the endogenous TCR-based immune synapse, but CART cells have the potential to demonstrate faster "on/off" rates than traditional TCR-based T cell cytotoxicity, although degranulation, stimulation, and kinetics of cytotoxicity are similar [33], which may reflect a less structured synapse.

\section{The transmembrane domain: in the right lane}

The influence of the CAR transmembrane is less well understood and interrogated. However, the CAR transmembrane domain exerts a function within the CART cell, if not only for lipid raft localization within distinct regions of the membrane. For instance, incorporation of the CD3 $\zeta$ transmembrane domain into the CAR enables homodimerization through naturally occurring residues and also CAR heterodimerization with the TCR complex [34]. Abrogating CAR dimerization reduces antigen sensitivity, suggesting that the local interactions of the CAR with other signaling molecules influences CAR function. It is now necessary to understand the influence of $\mathrm{CD} 8 \alpha$ and $\mathrm{CD} 28$ transmembrane domains, two of the most utilized transmembrane domains, on CAR function. 


\section{The costimulatory domain: pedal to the metal}

The costimulatory domain of the CAR is arguably the most influential portion of the CART cell engine. Proper costimulation affects effector functions, including cytokine production, memory differentiation, survival, persistence, and the metabolic capacities of the CART cell after stimulation. Clinically, CD28 and 4-1BB have been used in second-generation CARs, but many other costimulatory domains have been described pre-clinically, including ICOS, OX40, CD27, CD2, and GITR, that could provide insights into necessary CART functions for solid tumors. For instance, mesothelin-specific CART cells bearing an ICOS signaling domain demonstrate efficient anti-tumor responses in a mesothelioma xenograft model, enhanced CD4 $\mathrm{T}$ cell persistence and increased polarization of CD4 $\mathrm{T}$ cells towards Th17 phenotype, which may be advantageous as these cells are refractory to senescence after longterm ex vivo expansion [35, 36].

In the case of CD19-CART, 4-1BB costimulation endows the $\mathrm{T}$ cells with long-term persistence and durable control of leukemia, whereas CD28 costimulation, in CD19-CART and others, provides robust cytolytic activity but short-term persistence [37, 38]. Mechanistically, the enhanced persistence of 4-1BB-costimulated CART cells is likely due to enhanced fatty acid oxidation, increased central memory formation, and decreased exhaustion when compared to CD28-costimulated CART [39-41].

It is also important to note that until we can understand the added benefit of each CAR component, improved designs are derived empirically and must be considered in the context of the CAR components ( $\mathrm{scFv}$, hinge, costimulatory domain) and manufacturing procedures (viral vector, method of activation and expansion protocol). For example, several groups have noted tonic signaling of costimulated CARTs that can also drive exhaustion and decreased persistence [39, 41, 42]; however, some studies have implicated CD28 as a more tonic signaling costimulatory domain and others have implicated 4-1BB as such. There remain many variables between CART cells amongst institutions and generalizations about CARs should be limited until we gain an understanding of the intrinsic influences of CAR structural domains.

\section{Fueling the engine and boosting the nitro}

As single agents, CART cells will be confronted with major challenges in treating solid tumors, even with optimized targeting and CAR design. Unfortunately, the TME of solid malignancies is the perfect storm for preventing significant anti-tumor immune responses. It is therefore important to consider both cell-intrinsic and cell-extrinsic engineering strategies to overcome these barriers.

\section{Payload delivery}

Immunotherapists as early as William Coley and more recently, Lloyd Old have demonstrated that the delivery of adjuvants and cytokines into patients' tumors can induce anti-tumor responses and lymphocyte proliferation [43-46]. Pro-inflammatory cytokines are necessary fuel for activated $\mathrm{T}$ cells and can help in the recruitment of innate immune cells; however, systemic delivery of cytokines can result in lethal toxicities [47]. In an attempt to improve the safety of cytokine delivery, $\mathrm{T}$ cells can be engineered to secrete payloads directly in the TME, a strategy that takes advantage of natural tumor-homing properties of CART cells. Using this approach, CART cells have been developed preclinically to deliver IL-12 and IL-18, among other cytokines, directly within the tumor (Fig. 3) [48, 49]. CARTcells can also be loaded ex vivo with nanoparticles for in vivo delivery, which takes advantage of the diverse cargo that can be loaded into nanoparticles [50]. Studies have also described the delivery of therapeutic antibodies to the TME by CARTs (e.g., secretion of antagonistic anti-PD-L1) [51]. These strategies have all demonstrated enhanced engineered $\mathrm{T}$ cell responses, including higher proliferation, differentiation of memory cells, induction of innate cells, enhanced antigen presentation, and inhibition of immunosuppressive cells.

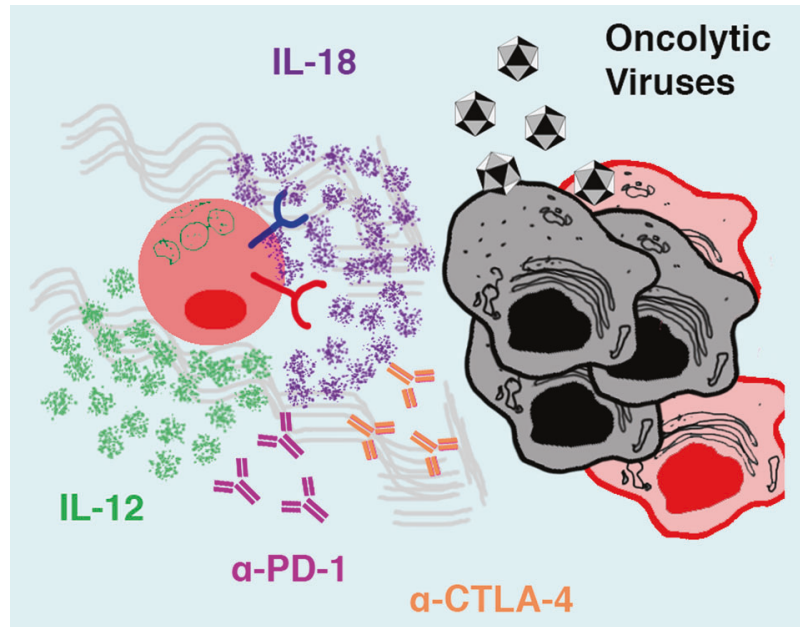

Fig. 3 Proposed methodology for improving CAR T cell eradication of solid tumors: CART cells can be administered with combinatorial therapies in order to target multiple antigens and induce a multitude of anti-tumor responses. The design of CARs is crucial to the supplying proper activation. CARTs can be engineered to delivery payloads of various cytokines, such as IL-12 and IL-18, or antibodies, such as antiPD-1 and anti-CTLA-4. Combination of CART cells and oncolytic viruses can promote tumor debulking, epitope spreading, and drive strong immune responses 


\section{Fine-tuning delivery}

Tactics to fine-tune the expression and delivery of attractive molecules by CART cells are necessary to enhance the safety in solid tumors where surrounding normal tissues must be spared. These inducible systems, including those with tetracycline-responsive promotors (Tet-on/Tet-off) and cleavable receptor systems such as the previously described SynNotch system [52], can be utilized to induce a customized cytokine cocktail upon antigen binding. Another method for tuning the $\mathrm{T}$ cell response involves the use of rapamycin-analogs to induce dimerization of split CAR components [53] or to induce rapid apoptosis of engineered $\mathrm{T}$ cells as a way to treat dose-limiting toxicities [54].

\section{Combination with checkpoint inhibition}

Various approaches have been described to overcome tumor immunosuppression and restore $\mathrm{T}$ cell function by modulating CTLA-4 and PD-1 [55-57]. Currently, the strongest responses have been observed in tumors with high somatic mutation load, or with high $\mathrm{CD} 8^{+} \mathrm{T}$ cell based infiltrates [58-61]. CART cells may complement anti-tumor efficacy in tumors with reduced immunogenicity or low $\mathrm{T}$ cell infiltration. As CART cells are also susceptible to the immunosuppression [62], strategies to combine CART with checkpoint blockade should be explored.

In mesothelioma xenograft models, mesothelinredirected CART cells can be inhibited upon antigen exposure within the TME $[62,63]$. Treatment with multiple modalities to block PD-1 signaling restored the effector function of CART cells in vivo. Others demonstrated that PD-1 blockade can enhance the efficacy of HER2-CART therapy while sparing normal organs in a human HER2transgenic immunocompetent mouse model [64]. In this model, PD-1 blockade modulated the immunosuppressive TME with a significant decrease in MDSC infiltration. Clinical observations also provide support for the combinational modality. Our group reported that PD-1 blockade induced durable responses in patients with refractory diffuse large B cell lymphoma (DLBCL) and progressive lymphoma after therapy with CD19-redirected CART cells [65]. After the administration of PD-1 blocking antibody, the patient achieved a clinically significant anti-tumor response and expansion of CART cells with decreased coexpression of PD-1 and Eomes. These observations suggest that checkpoint blockade may be effective and safe approaches for improving the efficacy of CART cell therapies. A clinical trial is currently evaluating the combination of ipilimumab and CD19-redirected CART in patients with B cell non-Hodgkin lymphoma, CLL, and BALL (NCT00586391).

\section{Combination with oncolytic virus therapy}

Oncolytic viruses $(\mathrm{OV})$ represent promising agents for the treatment of solid tumors. OV can be programmed to specifically target, replicate in and kill cancer cells while sparing normal cells. The release of virus progeny results in an exponential increase of the virus inoculum, which can cause direct tumor debulking while releasing Th1 and M1inducing pro-inflammatory molecules. The apoptotic tumor cells can serve as a target for cross priming tumor-specific immune responses, generating systemic anti-tumor immunity, including $\mathrm{T}$ cells that recognize tumor antigens through the TCR [66, 67]. Moreover, OV can be genetically modified to express therapeutic transgenes selectively in the TME $[68,69]$. The feasibility and safety of OV in human patients has been demonstrated in clinical trials [70-72].

In this regard, one oncolytic virus, talimogene laherparepvec (T-VEC) received FDA approval for the treatment of patients with melanoma [71]. T-VEC is an oncolytic virus derived from herpes simplex type-1 designed to selectively replicate within tumors and produce granulocyte macrophage colony-stimulating factor (GM-CSF) to enhance systemic anti-tumor immune responses. T-VEC showed significantly higher response rates than GM-CSF alone in patients with advanced melanoma without fatal treatmentrelated adverse events in a randomized phase III trial [71].

The ability of OV to revert tumor immunosuppression and express therapeutic transgenes locally provides a rational strategy for combination with CART cells. In addition, OV, CART, and TCR T cell combination therapy enables targeting of multiple TAAs and may overcome tumor heterogeneity and tumor escape caused by target antigen loss, which is a central issue for immunotherapy in solid tumors.

An oncolytic adenovirus (OAd) engineered to express RANTES and IL-15 enhanced the anti-tumor effect of GD2redirected CART therapy in xenograft mouse models [73]. Subsequently, it was demonstrated that by intratumoral coadministration of OAd and helper-dependent adenovirus (HDAds) expressing a PD-L1 blocking mini-body enhanced the anti-tumor activity of HER2-redirected CART in human cervical squamous cell carcinoma and prostate carcinoma xenograft mouse models [74]. Further modification of the HDAds to express PD-L1 blocking antibody and IL12p70 in combination with HER2-CART improved survival of the mice compared to either approach alone [75]. OV therapies improved the efficacy of CART in these studies by direct lysis or induction of apoptosis of tumors, activating and enhancing the cytolytic activity of CART, and improving the migration/infiltration and persistence of CART cells. These results strongly support the notion that oncolysis and local delivery of therapeutic genes by $\mathrm{OV}$ has the potential to overcome the tumor resistance against CART therapy in solid 
tumors. However, most of these observations are based on immunodeficient mouse models and further investigation using immunocompetent models may be required to understand immune interactions during combinational therapy that may be underappreciated in immunodeficient settings.

\section{Combination with agonistic anti-costimulatory receptor antibodies}

Agonistic anti-4-1BB mAbs can provide strong costimulatory signals to $\mathrm{T}$ cells and has increased anti-tumor responses of $\mathrm{CD}^{+} \mathrm{T}$ cells in several pre-clinical studies [76]. Third-generation CARs, which contain two costimulatory domains such as CD28 and 4-1BB, have been developed to further improve the efficacy and persistence of second-generation CARs. The combinational therapy of agonistic anti-4-1BB $\mathrm{mAb}$ and second-generation CART cells is an alternative approach to improve the function of second-generation CART cells. Mardiana et al. [77] demonstrated 4-1BB mAb significantly enhanced HER2-28ל CART cell efficacy with increased IFN $\gamma$ and Ki67 in tumor-infiltrating $\mathrm{T}$ cells in a Her2-transgenic immunocompetent mouse model. Moreover, anti-4-1BB $\mathrm{mAb}$ significantly reduced host immunosuppressive cells at the tumor, including Tregs and MDSCs.

Although the mechanisms by which anti-4-1BB mAb therapy induces change in immunosuppressive cells is not fully understood, the ability of mAbs to modulate the immunosuppressive TME is attractive for combination with CART therapy in solid tumors. This approach may also be safer than directly incorporated third-generation CART cells, as it enables dose adjusting to avoid toxicity.

\section{Other potential combination therapies}

Other possible strategies to improve the efficacy of CART therapies include combination with anti-tumor drugs that possess immunomodulatory effects. It has been reported that lenalidomide enhances the anti-tumor efficacy of EGFRvIII-redirected CART with the evidence of enhanced immunological synapses between $\mathrm{T}$ cells and target cells in a glioblastoma xenograft mouse models [78]. Inhibition of Bruton's tyrosine kinase (BTK) by ibrutinib also enhances the anti-tumor effect of CD19-redirected CART and leads to prolonged remissions in a xenograft model of mantle cell lymphoma (MCL) [79]. Currently, our group is conducting a pilot clinical trial testing the combination of ibrutinib with CD19-redirected CART (NCT02640209).

\section{Outlook on the future}

The elements of CART research described herein, while not exhaustive of the field of study, highlight the most important barriers to overcome hurdles that exist within solid tumors. Through precise and controlled engineering of the immune system, we can specify the targeting of the immune response, maximize the lytic ability and persistence of $\mathrm{T}$ cells, deliver payloads to alter the surrounding immunological milieu, and complement with best-in-class clinical strategies. As discussed here, many promising combination approaches have been described in pre-clinical models. These combinational approaches are feasible to translate to the clinic, as most agents already exist as single agents in the clinic and their safety and efficacy profiles are typically clear. Indeed, some of these combination therapies are currently being tested in the context of CD19-redirected CART therapies and clinical trials studying combination modalities in solid tumors may be expected shortly.

CART therapy for leukemia provided a proof-of-concept that these agents could sufficiently eradicate cancer. CD19CARTs have taught us the know-how of engineering $\mathrm{T}$ cells. Now, we must combine this knowledge with therapies that affect the innate immune system and tumor milieu.

\section{Compliance with ethical standards}

Conflict of interest CHJ reports grants from Novartis, outside the submitted work. In addition, CHJ has a patent 9464140, 9161971, 8975071,8916381 , and 8906682 , with royalties paid to Novartis, is a scientific founder of Tmunity Therapeutics, a biotech dedicated to developing engineered $\mathrm{T}$ cells for therapy of cancer, infections and autoimmunity, and has founders stock from Tmunity. CCK has ownership interests in patents held by Memorial Sloan-Kettering Cancer Center and licensed to Juno Therapeutics and Fate Therapeutics. ADP is an inventor on intellectual property owned by the University of Pennsylvania. The remaining authors declare that they have no conflict of interest.

Open Access This article is licensed under a Creative Commons Attribution 4.0 International License, which permits use, sharing, adaptation, distribution and reproduction in any medium or format, as long as you give appropriate credit to the original author(s) and the source, provide a link to the Creative Commons license, and indicate if changes were made. The images or other third party material in this article are included in the article's Creative Commons license, unless indicated otherwise in a credit line to the material. If material is not included in the article's Creative Commons license and your intended use is not permitted by statutory regulation or exceeds the permitted use, you will need to obtain permission directly from the copyright holder. To view a copy of this license, visit http://creativecommons. org/licenses/by/4.0/.

\section{References}

1. Fesnak AD, June CH, Levine BL. Engineered T cells: the promise and challenges of cancer immunotherapy. Nat Rev Cancer. 2016;16:566-81.

2. Hanahan D, Weinberg RA. Hallmarks of cancer: the next generation. Cell. 2011;144:646-74.

3. Gust J, Hay KA, Hanafi LA, Li D, Myerson D, Gonzalez-Cuyar LF, et al. Endothelial activation and blood-brain barrier disruption 
in neurotoxicity after adoptive immunotherapy with CD19 CAR-T cells. Cancer Discov. 2017;7:1404-19.

4. Overstreet MG, Gaylo A, Angermann BR, Hughson A, Hyun YM, Lambert K, et al. Inflammation-induced interstitial migration of effector CD4(+) $\mathrm{T}$ cells is dependent on integrin alphaV. Nat Immunol. 2013;14:949-58.

5. Tao JH, Barbi J, Pan F. Hypoxia-inducible factors in T lymphocyte differentiation and function. A review in the theme: cellular responses to hypoxia. Am J Physiol Cell Physiol. 2015;309: C580-589.

6. Kato Y, Ozawa S, Miyamoto C, Maehata Y, Suzuki A, Maeda T, et al. Acidic extracellular microenvironment and cancer. Cancer Cell Int. 2013;13:89.

7. Chen DS, Mellman I. Elements of cancer immunity and the cancer-immune set point. Nature. 2017;541:321-30.

8. Chung EY, Psathas JN, Yu D, Li Y, Weiss MJ, ThomasTikhonenko A. CD19 is a major B cell receptor-independent activator of MYC-driven B-lymphomagenesis. J Clin Invest. 2012;122:2257-66.

9. Jensen MC, Popplewell L, Cooper LJ, DiGiusto D, Kalos M, Ostberg JR, et al. Antitransgene rejection responses contribute to attenuated persistence of adoptively transferred CD20/CD19specific chimeric antigen receptor redirected $\mathrm{T}$ cells in humans. Biol Blood Marrow Transplant. 2010;16:1245-56.

10. Paszkiewicz PJ, Fräßle SP, Srivastava S, Sommermeyer D, Hudecek M, Drexler I, et al. Targeted antibody-mediated depletion of murine CD19 CAR T cells permanently reverses B cell aplasia. J Clin Invest. 2016;126:4262-72.

11. Brown CE, Alizadeh D, Starr R, Weng L, Wagner JR, Naranjo A, et al. Regression of glioblastoma after chimeric antigen receptor T-cell therapy. N Engl J Med. 2016;375:2561-9.

12. Carter P, Presta L, Gorman CM, Ridgway JB, Henner D, Wong WL, et al. Humanization of an anti-p185HER2 antibody for human cancer therapy. Proc Natl Acad Sci USA. 1992;89: 4285-9.

13. Drent E, Themeli M, Poels R, de Jong-Korlaar R, Yuan H, de Bruijn J, et al. A rational strategy for reducing on-target off-tumor effects of CD38-chimeric antigen receptors by affinity optimization. Mol Ther. 2017;25:1946-58.

14. Morgan RA, Yang JC, Kitano M, Dudley ME, Laurencot CM, Rosenberg SA. Case report of a serious adverse event following the administration of $\mathrm{T}$ cells transduced with a chimeric antigen receptor recognizing ERBB2. Mol Ther. 2010;18:843-51.

15. Caruso HG, Hurton LV, Najjar A, Rushworth D, Ang S, Olivares $S$, et al. Tuning sensitivity of CAR to EGFR density limits recognition of normal tissue while maintaining potent antitumor activity. Cancer Res. 2015;75:3505-18.

16. Liu X, Jiang S, Fang C, Yang S, Olalere D, Pequignot EC, et al. Affinity-tuned ErbB2 or EGFR chimeric antigen receptor $T$ cells exhibit an increased therapeutic index against tumors in mice. Cancer Res. 2015;75:3596-607.

17. Ahmed N, Brawley VS, Hegde M, Robertson C, Ghazi A, Gerken $\mathrm{C}$, et al. Human epidermal growth factor receptor 2 (HER2)specific chimeric antigen receptor-modified $\mathrm{T}$ cells for the immunotherapy of HER2-positive sarcoma. J Clin Oncol. 2015;33:1688-96.

18. Ahmed N, Brawley V, Hegde M, Bielamowicz K, Kalra M, Landi $\mathrm{D}$, et al. HER2-specific chimeric antigen receptor-modified virusspecific $\mathrm{T}$ cells for progressive glioblastoma: a phase 1 doseescalation trial. JAMA Oncol. 2017;3:1094-101.

19. Gattinoni L, Finkelstein SE, Klebanoff CA, Antony PA, Palmer DC, Spiess PJ, et al. Removal of homeostatic cytokine sinks by lymphodepletion enhances the efficacy of adoptively transferred tumor-specific CD8 + T cells. J Exp Med. 2005;202:907-12.

20. Ruella M, Barrett DM, Kenderian SS, Shestova O, Hofmann TJ, Perazzelli J, et al. Dual CD19 and CD123 targeting prevents antigen-loss relapses after CD19-directed immunotherapies. J Clin Invest. 2016;126:3814-26.

21. Wilkie S, van Schalkwyk MC, Hobbs S, Davies DM, van der Stegen SJ, Pereira AC, et al. Dual targeting of ErbB2 and MUC1 in breast cancer using chimeric antigen receptors engineered to provide complementary signaling. J Clin Immunol. 2012;32:1059-70.

22. Bielamowicz K, Fousek K, Byrd TT, Samaha H, Mukherjee M, Aware $\mathrm{N}$, et al. Trivalent CAR T-cells overcome interpatient antigenic variability in glioblastoma. Neuro Oncol. 2017;20: 506-518.

23. Slaney CY, von Scheidt B, Davenport AJ, Beavis PA, Westwood JA, Mardiana S, et al. Dual-specific chimeric antigen receptor $\mathrm{T}$ cells and an indirect vaccine eradicate a variety of large solid tumors in an immunocompetent, self-antigen setting. Clin Cancer Res. 2017;23:2478-90.

24. Hegde M, Corder A, Chow KK, Mukherjee M, Ashoori A, Kew $\mathrm{Y}$, et al. Combinational targeting offsets antigen escape and enhances effector functions of adoptively transferred $\mathrm{T}$ cells in glioblastoma. Mol Ther. 2013;21:2087-101.

25. Fedorov VD, Themeli M, Sadelain M. PD-1- and CTLA-4-based inhibitory chimeric antigen receptors (iCARs) divert off-target immunotherapy responses. Sci Transl Med. 2013;5:215ra172.

26. Kloss CC, Condomines M, Cartellieri M, Bachmann M, Sadelain M. Combinatorial antigen recognition with balanced signaling promotes selective tumor eradication by engineered $\mathrm{T}$ cells. Nat Biotechnol. 2013;31:71-75.

27. Lanitis E, Poussin M, Klattenhoff AW, Song D, Sandaltzopoulos $\mathrm{R}$, June $\mathrm{CH}$, et al. Chimeric antigen receptor $\mathrm{T}$ cells with dissociated signaling domains exhibit focused antitumor activity with reduced potential for toxicity in vivo. Cancer Immunol Res. 2013;1:43-53.

28. Roybal KT, Rupp LJ, Morsut L, Walker WJ, McNally KA, Park JS, et al. Precision tumor recognition by $\mathrm{T}$ cells with combinatorial antigen-sensing circuits. Cell. 2016;164:770-9.

29. Wilkie S, Picco G, Foster J, Davies DM, Julien S, Cooper L, et al. Retargeting of human T cells to tumor-associated MUC1: the evolution of a chimeric antigen receptor. J Immunol. 2008;180:4901-9.

30. Hombach A, Hombach AA, Abken H. Adoptive immunotherapy with genetically engineered $\mathrm{T}$ cells: modification of the IgG1 Fc 'spacer' domain in the extracellular moiety of chimeric antigen receptors avoids 'off-target' activation and unintended initiation of an innate immune response. Gene Ther. 2010;17:1206-13.

31. Hudecek M, Sommermeyer D, Kosasih PL, Silva-Benedict A, Liu $\mathrm{L}$, Rader $\mathrm{C}$, et al. The nonsignaling extracellular spacer domain of chimeric antigen receptors is decisive for in vivo antitumor activity. Cancer Immunol Res. 2015;3:125-35.

32. James JR, Vale RD. Biophysical mechanism of T-cell receptor triggering in a reconstituted system. Nature. 2012;487:64-69.

33. Davenport AJ, Jenkins MR, Cross RS, Yong CS, Prince HM, Ritchie DS, et al. CAR-T cells inflict sequential killing of multiple tumor target cells. Cancer Immunol Res. 2015;3:483-94.

34. Bridgeman JS, Hawkins RE, Bagley S, Blaylock M, Holland M, Gilham DE. The optimal antigen response of chimeric antigen receptors harboring the CD3zeta transmembrane domain is dependent upon incorporation of the receptor into the endogenous TCR/CD3 complex. J Immunol. 2010;184:6938-49.

35. Guedan S, Chen X, Madar A, Carpenito C, McGettigan SE, Frigault MJ, et al. ICOS-based chimeric antigen receptors program bipolar TH17/TH1 cells. Blood. 2014;124:1070-80.

36. Bowers JS, Nelson MH, Majchrzak K, Bailey SR, Rohrer B, Kaiser AD, et al. Th17 cells are refractory to senescence and retain robust antitumor activity after long-term ex vivo expansion. JCI Insight. 2017;2:e90772.

37. Maude SL, Frey N, Shaw PA, Aplenc R, Barrett DM, Bunin NJ, et al. Chimeric antigen receptor T cells for sustained remissions in leukemia. N Engl J Med. 2014;371:1507-17. 
38. Zhang T, Cao L, Xie J, Shi N, Zhang Z, Luo Z, et al. Efficiency of CD19 chimeric antigen receptor-modified T cells for treatment of B cell malignancies in phase I clinical trials: a meta-analysis. Oncotarget. 2015;6:33961-71.

39. Frigault MJ, Lee J, Basil MC, Carpenito C, Motohashi S, Scholler $\mathrm{J}$, et al. Identification of chimeric antigen receptors that mediate constitutive or inducible proliferation of T cells. Cancer Immunol Res. 2015;3:356-67.

40. Kawalekar OU, O'Connor RS, Fraietta JA, Guo L, McGettigan SE, Posey AD Jr., et al. Distinct signaling of coreceptors regulates specific metabolism pathways and impacts memory development in CAR T cells. Immunity. 2016;44:380-90.

41. Long AH, Haso WM, Shern JF, Wanhainen KM, Murgai M, Ingaramo $\mathrm{M}$, et al. 4-1BB costimulation ameliorates $\mathrm{T}$ cell exhaustion induced by tonic signaling of chimeric antigen receptors. Nat Med. 2015;21:581-90.

42. Gomes-Silva D, Mukherjee M, Srinivasan M, Krenciute G, Dakhova O, Zheng Y, et al. Tonic 4-1BB costimulation in chimeric antigen receptors impedes $\mathrm{T}$ cell survival and is vectordependent. Cell Rep. 2017;21:17-26.

43. Carswell EA, Old LJ, Kassel RL, Green S, Fiore N, Williamson B. An endotoxin-induced serum factor that causes necrosis of tumors. Proc Natl Acad Sci USA. 1975;72:3666-70.

44. Miller $\mathrm{CH}$, Maher SG, Young HA. Clinical use of interferongamma. Ann N Y Acad Sci. 2009;1182:69-79.

45. Nauts HC, Swift WE, Coley BL. The treatment of malignant tumors by bacterial toxins as developed by the late William B. Coley, M.D., reviewed in the light of modern research. Cancer Res. 1946;6:205-16.

46. Sim GC, Radvanyi L. The IL-2 cytokine family in cancer immunotherapy. Cytokine Growth Factor Rev. 2014;25: 377-90.

47. Leonard JP, Sherman ML, Fisher GL, Buchanan LJ, Larsen G, Atkins MB, et al. Effects of single-dose interleukin-12 exposure on interleukin-12-associated toxicity and interferon-gamma production. Blood. 1997;90:2541-8.

48. Hu B, Ren J, Luo Y, Keith B, Young RM, Scholler J, et al. Augmentation of antitumor immunity by human and mouse CAR T cells secreting IL-18. Cell Rep. 2017;20:3025-33.

49. Pegram HJ, Lee JC, Hayman EG, Imperato GH, Tedder TF, Sadelain M, et al. Tumor-targeted T cells modified to secrete IL12 eradicate systemic tumors without need for prior conditioning. Blood. 2012;119:4133-41.

50. Stephan MT, Moon JJ, Um SH, Bershteyn A, Irvine DJ. Therapeutic cell engineering with surface-conjugated synthetic nanoparticles. Nat Med. 2010;16:1035-41.

51. Suarez ER, Chang de K, Sun J, Sui J, Freeman GJ, Signoretti S, et al. Chimeric antigen receptor $\mathrm{T}$ cells secreting anti-PD-L1 antibodies more effectively regress renal cell carcinoma in a humanized mouse model. Oncotarget. 2016;7:34341-55.

52. Roybal KT, Williams JZ, Morsut L, Rupp LJ, Kolinko I, Choe JH, et al. Engineering $\mathrm{T}$ cells with customized therapeutic response programs using synthetic notch receptors. Cell. 2016;167:419-32. e416

53. Wu CY, Roybal KT, Puchner EM, Onuffer J, Lim WA. Remote control of therapeutic $\mathrm{T}$ cells through a small molecule-gated chimeric receptor. Science. 2015;350:aab4077.

54. Zhou X, Di Stasi A, Brenner MK. iCaspase 9 suicide gene system. Methods Mol Biol. 2015;1317:87-105.

55. Garon EB, Rizvi NA, Hui R, Leighl N, Balmanoukian AS, Eder JP, et al. Pembrolizumab for the treatment of non-small-cell lung cancer. N Engl J Med. 2015;372:2018-28.

56. Hodi FS, O'Day SJ, McDermott DF, Weber RW, Sosman JA, Haanen JB, et al. Improved survival with ipilimumab in patients with metastatic melanoma. N Engl J Med. 2010;363: 711-23.
57. Motzer RJ, Escudier B, McDermott DF, George S, Hammers HJ, Srinivas $\mathrm{S}$, et al. Nivolumab versus everolimus in advanced renalcell carcinoma. N Engl J Med. 2015;373:1803-13.

58. Alexandrov LB, Nik-Zainal S, Wedge DC, Aparicio SA, Behjati $\mathrm{S}$, Biankin AV, et al. Signatures of mutational processes in human cancer. Nature. 2013;500:415-21.

59. Meng X, Huang Z, Teng F, Xing L, Yu J. Predictive biomarkers in PD-1/PD-L1 checkpoint blockade immunotherapy. Cancer Treat Rev. 2015;41:868-76.

60. Snyder A, Makarov V, Merghoub T, Yuan J, Zaretsky JM, Desrichard A, et al. Genetic basis for clinical response to CTLA-4 blockade in melanoma. N Engl J Med. 2014;371:2189-99.

61. Tumeh PC, Harview CL, Yearley JH, Shintaku IP, Taylor EJ, Robert L, et al. PD-1 blockade induces responses by inhibiting adaptive immune resistance. Nature. 2014;515:568-71.

62. Moon EK, Wang LC, Dolfi DV, Wilson CB, Ranganathan R, Sun $\mathrm{J}$, et al. Multifactorial T-cell hypofunction that is reversible can limit the efficacy of chimeric antigen receptor-transduced human T cells in solid tumors. Clin Cancer Res. 2014;20:4262-73.

63. Cherkassky L, Morello A, Villena-Vargas J, Feng Y, Dimitrov DS, Jones DR, et al. Human CAR T cells with cell-intrinsic PD-1 checkpoint blockade resist tumor-mediated inhibition. J Clin Invest. 2016;126:3130-44.

64. John LB, Devaud C, Duong CP, Yong CS, Beavis PA, Haynes $\mathrm{NM}$, et al. Anti-PD-1 antibody therapy potently enhances the eradication of established tumors by gene-modified $\mathrm{T}$ cells. Clin Cancer Res. 2013;19:5636-46.

65. Chong EA, Melenhorst JJ, Lacey SF, Ambrose DE, Gonzalez V, Levine BL, et al. PD-1 blockade modulates chimeric antigen receptor (CAR)-modified $\mathrm{T}$ cells: refueling the CAR. Blood. 2017;129:1039-41.

66. Tahtinen S, Gronberg-Vaha-Koskela S, Lumen D, MerisaloSoikkeli M, Siurala M, Airaksinen AJ, et al. Adenovirus improves the efficacy of adoptive T-cell therapy by recruiting immune cells to and promoting their activity at the tumor. Cancer Immunol Res. 2015;3:915-25.

67. Brown MC, Holl EK, Boczkowski D, Dobrikova E, Mosaheb M, Chandramohan V, et al. Cancer immunotherapy with recombinant poliovirus induces IFN-dominant activation of dendritic cells and tumor antigen-specific CTLs. Sci Transl Med. 2017;9:eaan4220.

68. Fukuhara H, Ino Y, Kuroda T, Martuza RL, Todo T. Triple genedeleted oncolytic herpes simplex virus vector double-armed with interleukin 18 and soluble B7-1 constructed by bacterial artificial chromosome-mediated system. Cancer Res. 2005;65: 10663-8.

69. Varghese S, Rabkin SD, Liu R, Nielsen PG, Ipe T, Martuza RL. Enhanced therapeutic efficacy of IL-12, but not GM-CSF, expressing oncolytic herpes simplex virus for transgenic mouse derived prostate cancers. Cancer Gene Ther. 2006;13:253-65.

70. Kanerva A, Nokisalmi P, Diaconu I, Koski A, Cerullo V, Liikanen I, et al. Antiviral and antitumor T-cell immunity in patients treated with GM-CSF-coding oncolytic adenovirus. Clin Cancer Res. 2013;19:2734-44.

71. Andtbacka RH, Kaufman HL, Collichio F, Amatruda T, Senzer N, Chesney J, et al. Talimogene laherparepvec improves durable response rate in patients with advanced melanoma. J Clin Oncol. 2015;33:2780-8.

72. Kim KH, Dmitriev IP, Saddekni S, Kashentseva EA, Harris RD, Aurigemma R, et al. A phase I clinical trial of Ad5/3-Delta24, a novel serotype-chimeric, infectivity-enhanced, conditionallyreplicative adenovirus (CRAd), in patients with recurrent ovarian cancer. Gynecol Oncol. 2013;130:518-24.

73. Nishio N, Diaconu I, Liu H, Cerullo V, Caruana I, Hoyos V, et al. Armed oncolytic virus enhances immune functions of chimeric antigen receptor-modified $\mathrm{T}$ cells in solid tumors. Cancer Res. 2014;74:5195-205. 
74. Tanoue K, Rosewell Shaw A, Watanabe N, Porter C, Rana B, Gottschalk S, et al. Armed oncolytic adenovirus-expressing PDL1 mini-body enhances antitumor effects of chimeric antigen receptor T cells in solid tumors. Cancer Res. 2017;77:2040-51.

75. Rosewell Shaw A, Porter CE, Watanabe N, Tanoue K, Sikora A, Gottschalk S, et al. Adenovirotherapy delivering cytokine and checkpoint inhibitor augments CAR T cells against metastatic head and neck cancer. Mol Ther. 2017;25:2440-51.

76. May KF Jr., Chen L, Zheng P, Liu Y. Anti-4-1BB monoclonal antibody enhances rejection of large tumor burden by promoting survival but not clonal expansion of tumor-specific CD8 + T cells. Cancer Res. 2002;62:3459-65.

77. Mardiana S, John LB, Henderson MA, Slaney CY, von Scheidt B, Giuffrida L, et al. A multifunctional role for adjuvant anti-4-1BB therapy in augmenting antitumor response by chimeric antigen receptor T cells. Cancer Res. 2017;77:1296-309.

78. Kuramitsu S, Ohno M, Ohka F, Shiina S, Yamamichi A, Kato A, et al. Lenalidomide enhances the function of chimeric antigen receptor $\mathrm{T}$ cells against the epidermal growth factor receptor variant III by enhancing immune synapses. Cancer Gene Ther. 2015;22:487-95.

79. Ruella M, Kenderian SS, Shestova O, Fraietta JA, Qayyum S, Zhang Q, et al. The addition of the BTK inhibitor ibrutinib to antiCD19 chimeric antigen receptor $\mathrm{T}$ cells (CART19) improves responses against mantle cell lymphoma. Clin Cancer Res. 2016;22:2684-96. 